\title{
Time, Social Theory and Media Theory: Contributions of Schutz to the understanding of new social realities
}

\author{
Ana Beatriz Martins, University of New South Wales \\ Victor Piaia, State University of Rio de Janeiro
}

\begin{abstract}
This article aims to contribute to the debate about time and the new social realities resulting from recent changes in the media field bringing social theory and media theory together. For this, we propose a rereading of a well-known author in social theory: Alfred Schutz. Schutz was one of the most productive authors of social theory and designed a broad theoretical framework involving many aspects of social life. He also emphasized the importance of media and brought significant contributions to the debate through the discussion of the concept of time. The author did not think time only descriptively, but opened a deep and conceptual dialogue that, we believe, is useful for understanding new social realities brought by the internet, both for media theories and social theories. The article has two sections, each corresponding to an approach to time made in Schutz, and in media theories and recent social theories. The first one focuses on a possible acceleration of time and the second one discusses the relation of time to memory. We bring Schutz's contributions to these phenomena, fostering the debate between social theory and media theory, as well as contributing conceptually to recent reflections.
\end{abstract}

\section{KEYWORDS}

Time, Acceleration, Memory, A Schutz, Media

\section{Introduction}

Much of contemporary sociological theory has been slow to incorporate media studies and their impacts on social relations in Sociology. Schroeder pointed to the weak consensus in the Social Sciences about the impact of the recent changes brought by new technologies (specially the internet) in our societies. He also warned that "Sociology has - with few exceptions - left the study of new media to the discipline of Media and Communications" (Schroeder, 2018, 1).

Media theories, on the other hand, while giving significant attention to the effects of media and its complexity in recent years, have been - sometimes - overly concerned with how media has spread and influenced other fields of social institutions (Sodre, 2014), such as Politics 
(Stromback, 2008), War (Horten, 2011), and Religion (Hjarvard, 2011). The consequence is inadequate development of this theoretical framework and a very descriptive approximation of phenomena. Couldry and Hepp, in their recent book "The Mediated Construction of Reality" pointed out this problem, and went further, showing a lack of dialogue between these two fields (Couldry and Hepp, 2017). Also, they claimed that social theory would not have longevity unless it turns to this dialogue and gives more importance to the phenomena currently studied by Communication and Media Studies (Couldry and Hepp, 2017, 12).

This article assumes - following Couldry and Hepp (ibid.) - this lack of dialogue, and that it is a problem, since a theoretically informed media theory could better analyse the new phenomena using concepts from social theory as a tool to instrumentalise the discussion in a more theoretical and systematic way. On the other hand, communication and media theories could help social theory to give proper importance to non-physical relationships by analysing our societies and the profound changes it is undergoing. So, the purpose of this article is to offer ways of bringing these two elements together. To do so, we propose a rereading of time approach via Alfred Schutz.

The discussions about time can contribute to the creation of bridges between these two areas of study (social theory and media theories), once temporality is a constitutive dimension of the construction of reality, and a fundamental element for the structuring of the two disciplinary fields. In Social Theory, we can see this dimension of time since the classical sociology, more directly with Durkheim (1903) and Simmel (1902), to the contemporary sociology with Elias (1984), Luhmann (1976, 1995), Giddens (1984, 1990), Adam (1990), Baert (1992), Urry (1996), among others. In Media Theory, we can see this dimension of time as well with McLuhan (1964), Augé (1996) and Virilio (2006).

Time is also an element that both areas have addressed in recent years when dealing with the changes brought about by new technologies, as seen in the writings of Rosa (2013), Adkins (2018), Hassan (2007, 2009 and 2010), Castells (2009), Schroeder (2018), Keightley (2012), Wajcman (2014) and Levy (2000). Schutz, in particular, is one of the main authors to articulate the centrality of space-time displacement of mediated interactions and its importance for the experience of individuals. The profound interweaving between new communication and information technologies and everyday life radicalizes the social impact of the temporal disengagement typical of mediated interactions. In this sense, Schutz's contributions on the subject of time can help to re-establish a more constant dialogue between media theories and social theory, in addition to symbolizing a common theme around which we can discuss contributions from both fields.

The new technologies brought changes in the way that we elaborate on the concept of time, and it is commonly discussed from two perspectives: Time and Acceleration, and Time and Memory. These are two main dimensions that constitute the temporal experience and have been the focus of several reflections that seek to understand the impact of new technologies. The first approach discusses the scope of subjectivity, that is, the current sense of acceleration of time, routines, and interactions, as well as the paradox of having "more time" (under new 
technologies) and feeling with "less time". What are the causes of this acceleration? How to conceptualise these changes?

The second approach discusses the reality construction and the action orientation: how have new ways of accessing memory changed social dynamics? How has this changed our relationship with the past and present? These two approaches (memory and acceleration) are connected, as will see below. Memory, since the advent of the internet, is built differently, and affects our reflection on time and space, pushing us out of the pure durée and making us more reflexive, giving us the sensation of acceleration.

These two ways of thinking about time (in relation to new technologies) are explored, respectively, in the two sections of this article. In them, we give a brief presentation of how the approaches have been constructed; what are the interpretative and theoretical advances that have been made for the understanding of this phenomenon, highlighting the problems that remain unanswered; and we offer some ideas present in Schutz's work that can respond and contribute to each of them. At the end of the article, we systematically return to the questions posed, as well as the answers offered.

\section{Time and Acceleration}

There is a common consensus that time would today be at a different pace compared to a few years ago and that time is accelerating. It is not uncommon to see people on the streets and in casual encounters commenting on how fast time is passing, how they do not have time for activities A or B, or how much time pressures them at a fast pace. Within a double hermeneutic process (Giddens, 1984), the elaboration of time acceleration, as well as its consequences, has become one of the main themes relating to new communication technologies and time. This theme generally reflects the hypothesis of acceleration of individual experiences. Its central argument is linked to the ability of technological devices to accelerate processes and interactions, compressing stimuli and responses to a temporality that is increasingly close to face-to-face contact.

This topic of temporal acceleration (or simultaneity) has been worked out by leading social science authors (such as Simmel, 1902; Giddens, 1990; Castells, 1996; and Urry, 2000) and can be generally divided between those who analyse this change in a structural way and those who favour the impacts of change on the individuals' experiences. That is, among those who thought time within a macro dimension, relating it to history and the great processes that occurred in society; and those who thought about time within a micro dimension relating it to everyday experience.

The first group worked on the notion of time and its recent acceleration from the perspective of how new communication technologies would be at the heart of recent structural transformations in the fields of economics, financial markets, politics, as well as patterns of production and consumption, introducing a new rhythm to the dynamics of these fields, specifically. Here, we highlight works by Adkins (2018) on time and the financial market, Laclau (1990) on time, socialism and democracy, and Castells (2009) on time and capitalism. The second group, on the other hand, starts with the acceleration brought by technological 
innovations to think about how they impact the individual's experiences (which, however, does not mean that they think just on individual level). Some (such as Hartmut Rosa) though about the structural level as well. One of the main concerns of these authors is the so-called timepressure paradox, which refers to the paradox of having more free time - since new technologies collaborate in the accomplishment of various daily tasks - and feeling pressured by a growing sense of lack of time, as indicated by various researchers.

According to Rosa (2013), we can distinguish between: i) technological acceleration; ii) acceleration of social change, and iii) acceleration of the pace of life. The latter refers to the "speed and understanding of actions and experiences in everyday life". What is the relationship between them? Rosa says there is a paradox between the first and third: if technological acceleration means we need less time to do things, that should mean more free time (leaving the pace of life more relaxed). In this sense, insofar as acceleration is identified in the rhythm of life, it is possible to characterise our context from the idea of "acceleration society".

Judy Wajcman (2014) starts from Rosa's elaboration and seeks to identify the causes of this acceleration society, analysing the dynamics of technological innovation as an originally social process - that is, emphasising the social character of technological development and thus distancing herself from the perspectives of technological determinism. However, by focusing its concerns on rebutting the hypothesis of technological determinism, she ends up taking the idea that acceleration is the main consequence of technological development, without conducting a critical reflection on what this acceleration means and how it should be interpreted (from individual experience).

It is possible to say that the problem of acceleration and changing the pace of time lies in some key questions: What is the role of new technologies in this discussion? Are new technologies the cause of the acceleration of time? What are the consequences of time acceleration for the lives of individuals in particular and society in general? How can we organise this discussion without neglecting the role of new technologies while resisting the explanatory impoverishment of technological determinism?

The authors above have sought answers, however using as a presupposition the a priori existence of acceleration. That is, they start from the given existence of acceleration, and from it think of the causes and consequences. None of the above authors question whether or not there is a change in the pace of time, nor do they question why - as individuals and institutions - we have this sensation, or whether our lives have been changed by it. The problem, according to Keightley (2013) and Hassan and Purser (2007), is that this kind of analysis is very superficial, as it leaves unexplained the deep connection of the speed of time and, as a result, the interpretation and analysis of the ways in which technology has affected our relationship with time is also hampered.

What we are going to do in this first section is ask ourselves just that, returning to the starting point What causes us - as individuals and society - to feel that time is accelerating? What are the social mechanisms involved in this supposed acceleration that impact so profoundly on both the micro and macro dimensions of social life? How can Schutz help us, theoretically and 
conceptually, to answer these questions? We argue in this section that the development and popularisation of new technologies propel the individual out of pure durée into the space-time dimension. It is marked, as we have seen, by a reflection on time. As we are encouraged to step out of this flow and reflect on our experience over time, the sense of acceleration sets in, as well as the social pressure that comes as a consequence of it.

In his discussion of time, Schutz uses a distinction previously sketched in Henry Bergson's work between two dimensions, namely the dimension of experience and the space-time dimension (Bergson, 1944). Bergson indicates in his work that the difference between experiences flowing in their pure duration and discontinuous images in the space-time world is due to these two levels, two dimensions of consciousness (Schutz, 1970). The individual and their ego can be in both dimensions, depending on the moment and the situation. In the dimension of pure durée, of flow, the ego dissolves into continuous transitions, and does not differentiate between different temporal moments, and does not reflect upon it. Already in the spatiotemporal dimension, the individual leaves the pure durée, and claims the reflection on time and their experience with it. Thus, Schutz states that all distinctions, all attempts to separate individual experiences from the unity of duration, are artificial, for when I immerse myself in my stream of consciousness, in my durée, I do not find any kind of differentiated experience. It lights up, goes out, new ones appear, and others disappear from the old, making it impossible for the actor to distinguish between now and moments past, since experience is a one-way and irreversible flow (Schutz, 1945).

Of course, it is possible to know, for example, that time has passed and we are older now, however that does not mean we know exactly 'when' it happened, as this cannot be known when we are within the flow, for the consciousness of the durée flow presupposes interruption (and reflection) of the flow itself. This reflection and interruption can be thought of as a remembrance (back in the past). Schutz takes this idea of reflexivity further, and it becomes one of his main points. Systematically, what Bergson (and Schutz) seems to want to affirm from these reflections is that there are two dimensions: a spatiotemporal dimension, which is by definition - the dimension where there are reflection and a retrospective look at life and phenomena, as well as clipped assessment of time; and a dimension of experience within which everything is flow. In the first, there is a discontinuous image; in the second, a pure durée. For Schutz, the difference between these two dimensions lies in consciousness.

If the basis for the difference between them is not objective but present in the stream of consciousness, it would not be entirely correct to say that in one dimension there is a difference between successor and previous moments, while in the other there is none. In fact, in one dimension there is awareness of this difference since an individual has come out of the flow and done an exercise in reflection, and in the other - with consciousness immersed in duree this awareness doesn't exist. Because of this, the differential of the dimensions would be the positioning of the individual out of the continuum, where the same - reflexively - strengthens with the ability to notice the temporal differences between what happened and what remained. Despite the general construction, it is possible to make an effort to understand Schutz's elaboration in our daily lives. After all, often submerged in the pure durée of everyday life, we 
do not necessarily realise the passage of time, and do not distinguish between present, past, and future so clearly.

However, when we stop to reflect on our existence (sometimes on a birthday or festive date), we leave the pure durée and are inserted into a spatial and temporal dimension, which leads us to categorise facts and events in order to distinguish space-time variations. This is very interesting because it assumes that the end of a phase does not depend on the phase itself. In other words, the idea of the end is not ontological to the idea of phase. It seems to depend on the actor's interpretation of how they live their experience. That is, time seems to be strictly linked to the idea of the experience. Also, this notion seems to have some impact on Schutz's work, since the idea of experience is one of the strongest and most prevalent in its formulation. What Schutz does not systematise, however, is how these dimensional passages happen in everyday life. Moreover, Schutz does not elaborate whether, depending on the society or the number of stimuli the individual receives, these outputs in the spatiotemporal dimension become more or less frequent.

The conceptualisation that Bergson outlines and which Schutz systematises could serve as a basis for thinking about the acceleration of time. This acceleration would no longer be thought of as an obvious assumption, as socially given, but as a complex mechanism through which individual consciousnesses are stimulated to move from the pure flow of social experience to continuous reflection on time and space.

Several studies highlight the number of stimuli as one of the most striking effects of accelerated technological development. The works on the decentralization of content in the web show information flooding as one of its main characteristics (Andrejevic, 2013; Dahlgren, 2018). Andrejevic and Dahlgren argue that the amount of information produced and circulated on the internet exhausts human consumption and processing capacity. Social media amplify this process by imposing, in different ways, the insertion and understanding of subjects that would not be consumed outside it. In this sense, political discussion groups on Facebook or WhatsApp, as well as Twitter trending topics, "push" individuals into debates and the consumption of unsolicited information (Gil de Zúñiga and Diehl, 2019). The "analogue" repercussions of the digital discussion dramatize the imposition by continually updating it, under penalty of social, professional sanctions, among others.

Informational abundance, in this sense, is just one of the elements that pressure conscience from the number of stimuli. This process also occurs concerning the intensity of interactions established in daily life, in ways of conduct in front of and within different virtual environments, in advertisements and in notifications from various applications, among others. This reflection, when performed continuously and repeatedly, brings the constant sensation of the passage of time, and therefore replaces (or complexifies) the idea of acceleration with the idea of increasing reflexivity and entering the space-time dimension. In other words, we are arguing that the individual suffers an expulsion of pure durée (as described above) and starts to reflect about space and time dimension, having the sensation of acceleration more than before. 
The richness of Schutz's formulation lies in its theoretical-conceptual capacity, and therefore, explanatory power of a new social phenomenon. If before the popularization of the internet, as mentioned above, individuals performed this reflection exercise only in the face of the death of a loved one, or on commemorative dates, the exercise is now done daily, bringing individual and collective pressure and acceleration. The question that arises in the face of this new formulation is why or how do new technologies increase stimuli and demands for individuals to move out of durée and continuous flow into the space-time dimension? The answer to this lies in the broader discussion about new technologies and their impacts on everyday life. After all, much has been said about how the new devices have transformed the way we deal with memories, dating, time control, simultaneity, synchrony, diachrony, and space and time itself.

Being connected at all times to devices that forcefully make us record memories and dealing concretely and reflexively with the themes of space and time force us into the space-time dimension. Examples are notifications of birthdays, events and memories made by social networks such as Facebook; instant markings made by mobile devices about their location in space and time; notifications on instant messaging applications, among other stimuli. These stimuli force us to move more and more constantly out of the dimension of experience and drive us both to the most frequent reflections about space-time and to what Bergson calls psychic tension. What once resembled a rhythmic, relaxed coming-and-going between one dimension and another of individual and collective consciousness now translates into psychic tension on both the individual and social levels, generating - perhaps - what extant literature describes as a time-pressure paradox.

\section{Time and Memory}

As discussed in the previous section, the debate on new technologies and acceleration is the primary approach of the social sciences about transformations in time conceptions. This emphasis, however, eventually obscures other dimensions of temporality that are also affected by communicative changes. One is the debate on the formation of individual and collective memories in a context of deep mediatization (Couldry and Hepp, 2017).

The literature on memory in the social sciences is vast and consensual in the sense of thinking of memory as a constant process of construction and reconstruction (Schutz, 1967; Giddens, 1984, 1995). Thus, past events and experiences would not be fixed references, but ideas and perceptions subject to reinterpretation according to the interactions and stimuli of the present. The construction of memory was deeply affected by media innovations, which allowed the recording of moments and experiences that were previously transmitted only by orality. In this sense, books, diaries, photographs, videos and audios are media supports for the construction of our memories, as well as places, music and movies can also be. That is, memory can be composed of elements produced by individuals as well as elements external to them (Jones, 2006; Keightley, 2012; Keightley and Pickering, 2017).

What, then, would be the changes in the context of deep mediatization? How does the exponential increase in record production and increased access to sensitive content change the way we build our memories? How are collective memories constructed in this context? Using 
the concept of domestication, Keightley $(2012,2013)$ proposes an analysis of the construction of mediated time that escapes technological determinism, and that occurs in the integration of media time and everyday lifetime. In a critical stance, however, it identifies that empirical research on the concept of domestication falls on themes of private life, leaving aside the growing intertwining of the temporalities of public and private dynamics as a result of the domestication process itself.

The author departs from Bergson's definition of durée (continuous flow of the real) to argue supported by Middleton and Brown (2010) - that the elements of the experience of the flow of the real are relative to our particular perspectives, not realities itself. That is, based on the idea - in Bergson - of a model of temporal experience in which time can only be experienced through reflection, the author argues in favour of using the idea of 'zones of indetermination'. Zones of indetermination are places of interaction between temporalities. Keightley argues that we should consider media and text technologies as temporal logics of distinct durations that contribute to these zones of indetermination. The interdependence and interpretation of these different media dimensions have provided conditions for temporal experiences that go beyond the action situated in a specific time and space. The horizon opened by her is undoubtedly too fertile to complexify the understanding of new technologies and how they impact daily life. However, her approach is restricted to a dimension linked to memories and belonging, focusing on their dialogue with identity and affective issues.

This section wishes to go a little further, and - from the concept of the stock of knowledge developed by Alfred Schutz - to think about memories and the constitutive aspects of the subjectivity of individuals as a central element for guiding practical action in everyday life. Therefore, we assume that memory is the mainstay of anticipation so that if there are changes in the way memory is constructed, there are also significant repercussions on the horizon of action of individuals. To think about memory and action is essential to bringing two core concepts that Schutz inherits from Husserl and that enable the flow of lived experience from now to the next (as a continuum): protection and retention. All experience, for the author, is accompanied by retention, that is, a primary memory about it. As we move from now to the next now, the individual retains a memory of their experience. The sum of this movement constitutes a continuous process since there is a formation of memory and various retentions (Schutz, 1959a).

There is, however, a point at which such retentions and memories sometimes become weak and fade. Protection is a tension towards a moment or a moment to follow, a kind of prolonging the current moment. Both - secondary memory and anticipation - relate to past and future conceptions of time. Remembering, as an exercise in reconstruction, makes the past a present experience because it reactivates it and brings it to the now. Anticipating refers to the future because it brings for the present an expectation about what will come. In this way, we retain, produce, anticipate and protect, forming consciousness (Schutz, 1967). The formation of consciousness, therefore, relates directly to memories. Undeniably, new technologies have changed the way we rebuild our memories and the way we deal with the past, remember it, and anticipate the future. This new way, therefore, implies a transformation of the formation of 
one's consciousness. However, what is the implication of this for the individual and for society in a practical way?

The conceptual key to answering this provocative question lies in the idea of stock of knowledge. Schutz's stock of knowledge is the basis for social life, as the individual guides their action, reaction, or response to different situations based on their stock of knowledge. In general, we can define the stock of knowledge as a set of shared knowledge, lifelong knowledge, and memories used by the individual to act (Schutz, 1967). The stock of knowledge is partly shared by the society to which the individual belongs, and partly formed in a particular and individual way from the individual's own experiences. It serves as the basis for interactions between people, and it means that when the stock of knowledge changes, there is also a change in the interpretation of reality, and - ultimately - in reality, itself. Individuals, therefore, store individual and collective experiences, forming their experience stocks. This stock is always at hand, ready for use, serving as the basis for individual and therefore, collective action. The basis for the formation of this stock is the memory, which undergoes constant and profound transformation with the development and popularization of digital devices.

Perhaps from this conceptual and theoretical assumption, it helps to think of memory not only as a place of memories but as a place of action and social change. If we think from this perspective, the changes generated by new technologies are not limited to a more accurate recollection of what happened in the past but become relevant and decisive for the formation of individual and social consciences, and consequently for the formation of social life in all aspects. Two phenomena are fundamental to thinking about these changes: i) the increase in the number of action records - in the format of a digital text - in mediated interactions, ii) the selective or accidental exposure of own or others' generated content.

As identified by Zuboff $(1982,1985)$ there is an increase in computer-mediated interactions accompanied by the production of a stock of register, called by her 'electronic text'. This electronic text (which also refers to any other audiovisual media) contains information about the interaction that occurred: from the content itself to data about time, place, amount of words used, file size sent, among others. Zuboff (2019) focuses her reflection on how this data and metadata are used as instruments of surveillance and domination, highlighting how data economics is today one of the main transformations of capitalism. Zuboff's perspective emphasizes a more strategic and political side of the world in which computer-mediated interactions become increasingly frequent. However, the production of electronic texts may illuminate other consequences of the expansion of mediated interactions.

From a memory building point, social networks and instant communication apps serve as memory and record spaces in which trivial and meaningful actions are stored. The stories are built from interactions established between individuals on closed or open platforms (such as chats or timeline posts) and, depending on the platform, can be easily accessed by the user or others. Thus, we can say that, at least in this sense, interactions have a less ephemeral character and can be revisited whenever necessary. Added to this is the fact that social networks like Facebook and Twitter have tools that induce individuals to expose opinions and preferences indirectly, through likes, shares, and reactions. This type of record differs from posts in which 
individuals debate or make a public argument about a given subject, but it continues to add up to the amount of user-generated memories.

The growing production of social media records, along with the dynamics of news feeds on social networks like Facebook and Twitter, leads us to the second phenomenon that amplifies changes in memory production: accidental exposure to content (Fletcher and Nielsen, 2017; Boczkowski, Mitchelstein, and Matassi, 2018). Studies on this topic show that news feeds expose us to content we are not looking for, which, we argue, would lead to increased stimuli and records for individuals' knowledge stock. That is, the practical action of individuals inseparable from their stock of knowledge - is profoundly affected by the dynamics of new technologies and social networks, which significantly increase the production and exposure to actions, opinions and tastes of others through electronic records.

In this sense, it is possible to say that the impact of new technologies on the temporal dimension affects not only the sphere of memories, belongings and identities but also all the interactions that we establish in everyday life. Schutz's contribution from the idea of stock of knowledge is therefore central to understanding the social dynamics after the development and popularization of electronic devices, as well as central to understanding the role of memory, and the dynamics that derive from it.

\section{Conclusion}

This article used as a starting point the problem enunciated by Couldry and Hepp (2016) about the lack of dialogue between social theory and media studies. The dialogue between these two fields would be essential because of (i) the recent changes in the social world brought about by the new technologies and media, and (ii) the expertise of social theory in systematically thinking about the experiences of individuals and their interactions in society. In this article we have proposed as an ultimate goal contributing to these two fields by bringing them in dialogue. To do so, we worked with a common topic between these two areas: time. And to discuss it, we proposed a rereading of Alfred Schutz.

We presented two approaches to time that are common within the fields of social theory and media theory: (i) time and acceleration; and (ii) time and memory. We also presented the debate, the advances made, and the problems and issues that remain with little dialogue or response. Our reading of Schutz was based on this discussion and the unanswered questions so far. In the first section, we brought a bibliographical discussion that points to an acceleration of time, due - mostly - to technological and communicative advances. We highlighted the concept of Paradox Time-Pressure, elaborated from the paradox observed between having more time (due to the ease that new technologies offer us to perform some tasks) yet feeling less time. Despite the advances made by many authors, we observed that there was a central assumption that there is an acceleration of time, without questioning this acceleration or seeking to understand the mechanisms through which it is felt individually and collectively. 
With this in mind, we stepped back from the analysis, sought to understand the mechanism behind the possible acceleration of time, and proposed to do so through Schutz's conceptualization of the two dimensions of reality: space-time dimension and dimension of experience. Here is our big and original contribution. We called attention to the idea that what most authors called the acceleration of time (and designated as cause the new technological devices, without asking themselves exactly how this happens) can be thought of as a constant change from the dimension of experience, driven not only by the new devices, but by the use we make of them, leading to a constant reflection on time and space. Instead of assuming the acceleration of time, we proposed a more profound analysis through Schutz, thinking that the amount of stimuli brought by the new social media and the use we make of it causes more significant reflection and a constant need to get out of the flow of experience, bringing a feeling of acceleration.

In the second section, we discussed time in its relation to memory. We built on Keightley's efforts to think about how new technologies impact everyday life and how we construct our memories, identities, and affects. Drawing on Schutz and his concept of 'stock of knowledge', we also thought about how the new technologies and memory registered by them can serve as anticipation, that is, how the built memory resonates in the horizon of individual actions. Therefore, it can be said that this article answered - via Schutz's rereading - two fundamental questions related to new media and time, and contributed to bringing dialogue between social theory and media studies: (i) it provides an original and systematic conceptualization to serve as a conceptual tool for various empirical studies of media; and (ii) it brings to the centre of social theory - through the idea of action, experience and memory - the themes of media and the impact of new technological devices on individual and collective experience. For the dialogue between social theory and media theory to take place in an increasingly meaningful way, contributing to the understanding of new and recent social phenomena, we suggest the joint treatment (as was done here) of other central themes for both fields, in addition to revisiting the ideas of other authors (from both areas) capable of bringing a double contribution and helping to build an increasingly necessary dialogue.

\section{References}

Adam, B. (1990) Time and Social Theory. Cambridge: Polity Press.

Adkins, L. (2018) The Time of Money. Stanford: Stanford University Press.

Andrejevic, M. (2013) Infoglut: How too much information is changing the way we think and know. NY: Routledge.

Auge, M. (1996) Non-places: Introduction to an anthropology of supermodernity. In: Capital \& Class. Vol 20, Issue 3.

Baert, P. (1992) Time, Self and Social Being: outline of a temporalized sociology. Aldershot: Ashgate.

Bergson, H. (1944) Creative Evolution. New York: Random House Books. 
Boczkowski, P. J., Mitchelstein, E., \& Matassi, M. (2018) News comes across when I'm in a moment of leisure: Understanding the practices of incidental news consumption on social media. New Media \& Society, 20(10), 3523-3539.

Castells, M. (1996) The Rise of the Network Society, The information Age: Economy, Society and Culture Vol. 1. Malden, MA; Oxford, UK: Blackwell.

Castells, M. (2009) Communication Power. Oxford: Oxford University Press.

Couldry, N. and Hepp, A. (2016) The Mediated Construction of Reality. Cambridge: Polity Press.

Dahlgren, P. (2018) Media, Knowledge and Trust: The deepening epistemic crisis of democracy. The Public, 25:1-2, 20-27.

Durkheim, E. \& Mauss, M. (1903) Primitive Classification. Chicago: University of Chicago Press [1963].

Elias, N. (1984) Time: an essay. Oxford: Blackwell.

Fletcher, R., \& Nielsen, R. K. (2018) Are people incidentally exposed to news on social media? A comparative analysis. New Media \& Society, 20(7), 2450-2468.

Giddens, A. (1984) The Constitution of Society. Berkeley and Los Angeles: University of California Press.

Giddens, A. (1990) The Consequences of Modernity. Stanford: Stanford University Press.

Giddens, A. (1995) Politics, Sociology and Social Theory: Encounters with Classical and Contemporary Social Thought. Cambridge: Polity Press.

Gil de Zúñiga, H., \& Diehl, T. (2019) News finds me perception and democracy: Effects on political knowledge, political interest, and voting. New Media \& Society, 21(6), 1253-1271.

Hassan, R. (2007) 'Network Time', in R. Hassan and RE Purser (eds.), Time and Temporality in the Network Society. Stanford: Stanford University Press.

Hassan, R. (2009) Empires of Speed: Time and the acceleration of politics and society. Supplements to the study of Time. Leiden: Brill.

Hassan, R. (2010) Social Acceleration and the network effect: A defense of social 'science fiction' and network determinism. The British Journal of Sociology 61(2): 356-374.

Hjarvard, S. (2011) The mediatisation of religion: theorising religion, media and social change, Culture and Religion, 12:02, 119-135. 
Horten, G. (2011) The mediatization of War: a comparison of the American and German Media coverage of the Vietnam and Iraq Wars, American Journalism, 28:4, 29-53.

Jones, A. (2007) Memory and Material Culture. Cambridge: Cambridge University Press.

Keightley, E. (2012) 'Making time: The social temporalities of mediated experience' in E Keightley (ed.), Time, Media and Modernity. Basingstoke: Palgrave Macmillan, pp. 201-223.

Keightley, E. (2013) From immediacy to intermediacy: The mediation of lived time, Time \& Society, 22:1, 55-75.

Keightley, E. \& Pickering, M. (2017) Memory and the Management of Change. Basingstoke: Palgrave Macmillan.

Laclau, E. (1990) New Reflections on the Revolution of Our Time. London, UK: Verso.

Lévy, P. (2001) Cyberculture. Minneapolis: University of Minnesota Press.

Luhmann, N. (1976) The future cannot begin: temporal structures in Modern Society. Social Research, vol 43, n 1, pp 130-152.

Luhmann, N. (1995) Social Systems. Stanford University Press.

McLuhan, M. (1964) Understanding Media: The Extensions of Man. New York: McGraw Hill.

Rosa, H. (2013) Social Acceleration: A new theory of Modernity (New directions in Critical Theory). Columbia: Columbia University Press.

Rosa, H. (2019) Resonance: A Sociology of Our Relationship to the World. Cambridge: Polity Press.

Schroeder, R. (2018) Social Theory after the Internet: Media, Technology and Globalization. UCL Press.

Schutz, A. (1959a) 'Husserl's importance for the Social Sciences', in: H. L. Van Brenda et al (orgs). Edmund Husserl, 1859-1959, pp 86-98. The Hague: Nijhoff.

Schutz, A. (1959b) Type and Eidos in Husserl's Late Philosophy, Philosophy and Phenomenological Research, 20:2, 147-165.

Schutz, A. (1962a) 'Phenomenology and the Social Sciences', in: A. Schutz, Collected Papers, p. 118-139. The Hague: Martinus Nijhoff.

Schutz, A. (1962b) 'On Multiple Realities', in: A. Schutz, Collected Papers, 207-259. The Hague Nijhoff. 
Schutz, A. (1967) The phenomenology of the social world. Evanston, IL: Northwestern University Press.

Schutz, A. (1972) Collected Papers 1: The Problem of Social Reality. New York, Springer.

Schutz, A. \& Luckmann, T (1973) The Structures of the Life-world. Vol 1. Evanston, IL: Northwestern University Press.

Schutz, A. (1975) 'Edmund Husserl's Ideas', in: A. Schutz, Collected Papers, vol 3, 15-39. The Hague Nijhoff, 1975.

Simmel, G. (1902) 'The Metropolis and Mental Life', in: Kurt Wolff (trans.), The Sociology of Georg Simmel, 409-424. New York: Free Press, 1950.

Sodré, M. (2014) A ciência do comum: notas para o método comunicacional. Petrópolis: Vozes.

Stromback, J. (2008) Four Phases of Mediatization: An Analysis of the Mediatization of Politics, The International Journal of Press/Politics, 13, 228. DOI:

10.1177/1940161208319097.

Urry, J. (1996) 'Perspectives on Time and Space', in B. Turner (ed), The Blackwell companion to social theory. Massachusetts: Blackwell Publishers.

Virilio, P. (2006) Speed and Politics. Los Angeles: Semiotext (e).

Wagner, H. R. (1977) The Bergsonian Period of Alfred Schutz, Philosophy and Phenomenological Research, 38, 187-199.

Wajcman, J. (2014) Pressed for Time: The Acceleration of Life in Digital Capitalism. Chicago: University of Chicago Press.

Zuboff, S. (1982) New worlds of computer-mediated work, Harvard Business Review, v. 60, n. 5, p. 142-52.

Zuboff, S. (1985) Automate/informate: the two faces of intelligent technology, Organizational Dynamics, v. 14, n. 2, p. 5-18.

Zuboff, S. (2019) The Age of Surveillance Capitalism: the fight for a human future at the new frontier of power. New York; Public Affairs.

\section{Biographies}

Ana Beatriz Martins is PhD in Sociology (2018), and researcher at the University of New South Wales. Her areas of interest are social theory and time.

Email: beatrizmartins0511@gmail.com 
Victor Piaia is a PhD candidate at the State University of Rio de Janeiro, researching the political effects of changes in everyday interactions.

Email: piaia.victor@gmail.com 